\section{The necessity to activate long-term ETD in Korea}

\section{Necessity to activate long- term ETD}

\author{
Hyoseob Lee
}

Korea Capital Market Institute, Yeongdeungpo-gu, Republic of Korea

\begin{abstract}
Purpose - This paper aims to provide the necessity to activate long-term exchange-traded derivatives (ETD) in Korea. In the era of aging, low interest rates and low economic growth, the investment demand for long-term financial products, and its hedging demand have steadily increased. Unfortunately, long-term ETD do not trade in Korea, and this study presents political suggestions to invigorate long-term ETD based on overseas cases and empirical analysis. Specifically, this study suggests the necessity to activate exchange traded funds (ETFs) options, long-term Korea treasury bond futures and options and long-term Volatility Index of Korea Composite Stock Price Index future and options. The introduction of those long-term ETD not only contributes to providing long-term investment and hedging vehicles but also reduces market inefficiencies in the Korean industry of ETFs, bonds and structured products.
\end{abstract}

Keywords ETF option, Bond futures and options, VKOSPI futures and options, Market efficiency

Paper type Research paper

\section{Introduction}

Global exchange-traded derivatives (ETD) market has steadily grown [1]. As you can see in Figure 1, the number of global ETD contracts in 2019 reached 34.5 billion, which was increased by $122.6 \%$ from 2007 (compound annual growth rate [CAGR] is $7 \%$ ). The trading volume of the global ETD market increased continuously from 2007 to 2019, except for the period between 2011 and 2012, when the Korean derivatives market has significantly shrunk reduced because of the strengthening regulation [2]. What is the main reason for the increase in the global ETD market? The enough volatility, size and liquidity of underlying markets are significant factors for the success of the ETD market [3]. Well-designed market microstructure and various types of investors are also critical success factors for the ETD market.

Despite the recent decline in market volatility (Figure 2), the global ETD market has steadily grown because of the growth of Asian markets and the increased participation of institutional investors with a long-term investment horizon. The volatility index (VIX) surpassed 50 in the global financial crisis, but has steadily declined and is currently stable between 12 and 20. The volatility index of developed countries also showed a similar pattern to VIX and has steadily declined. The volatility in emerging countries was relatively high, and both the hedging and speculative demand for ETD products in emerging markets has increased. As shown in Figure 3, thanks to the increased trading volume of the Chinese and

(C) Hyoseob Lee. Published in Journal of Derivatives and Quantitative Studies: 선물연구. Published by Emerald Publishing Limited. This article is published under the Creative Commons Attribution (CC BY 4.0) licence. Anyone may reproduce, distribute, translate and create derivative works of this article (for both commercial and non-commercial purposes), subject to full attribution to the original publication and authors. The full terms of this licence may be seen at http://creativecommons.org/ licences/by/4.0/legalcode

JEL classification - G13, G14
Received 4 May 2020 Revised 24 June 2020 Accepted 9 August 2020

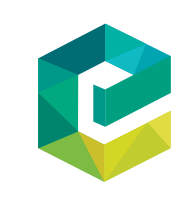

Journal of Derivatives and Quantitative Studies: 선물연구 ol. 28 No. 3, 2020

Emerald Publishing Limited e-ISSN: 2713-6647 p-ISSN: $1229-988 \mathrm{X}$ DOI 10.1108/JDQS-08-2020-0020 
JDQS

28,3

150

Figure 1.

Number of contracts of ETD
Figure 2.

Volatility index of VIX and VKOSPI
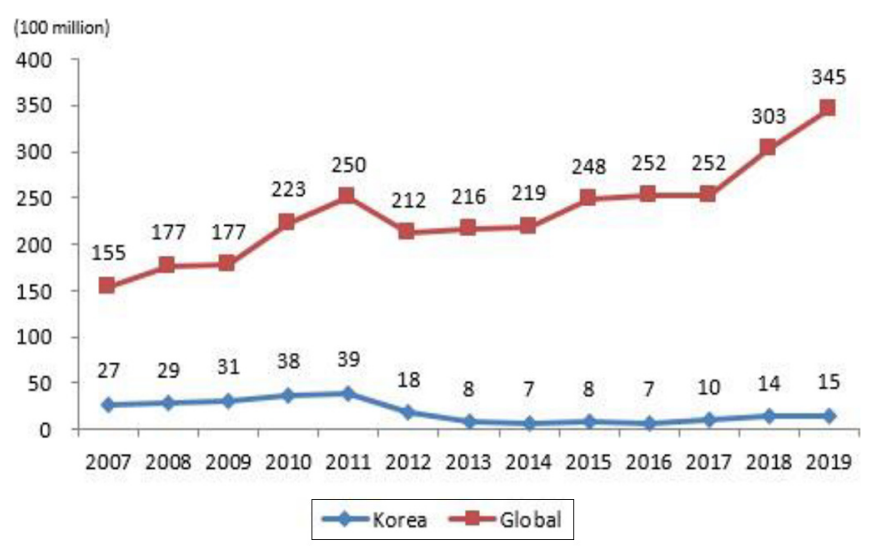

Source: Futures Industry Association (FIA)

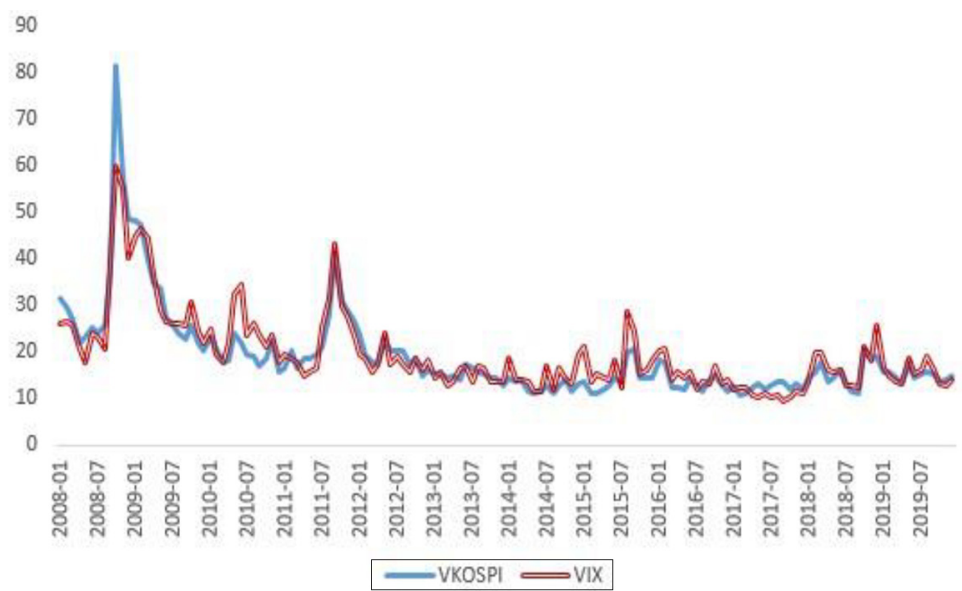

Source: CBOE, KRX

Indian ETD markets, the Asian market share in the global ETD market is steadily growing. The Asian market share increased from 33\% in 2014 to $42 \%$ in 2019, and the extra market share, which includes Latin America and Africa, also increased from 9\% to $11 \%$ during the same period. In contrast, the market share of North America and Europe decreased during the same period.

The equity index product is one of the main drivers for the increase of the global ETD market. Besides, the steady growth of other asset classes, such as interest rates, currency and commodity has a positive effect on the overall ETD market. As illustrated in Figure 4, owing to the fast growth of equity index ETD products listed in India and Brazil, equity index products have steadily increased in the past three years. The market share of equity index increased from $28 \%$ in 2016 to $36 \%$ in 2019 . The market share of interest rates and 


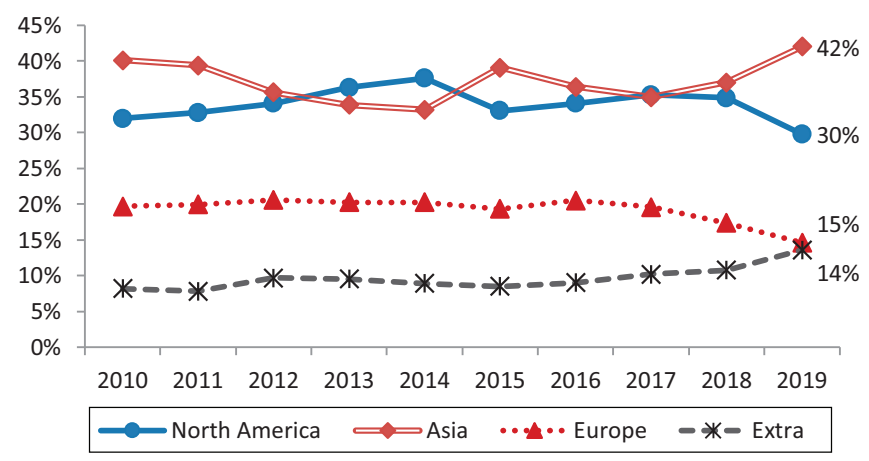

Necessity to activate longterm ETD

Source: FIA

Figure 3. ETD market share by region

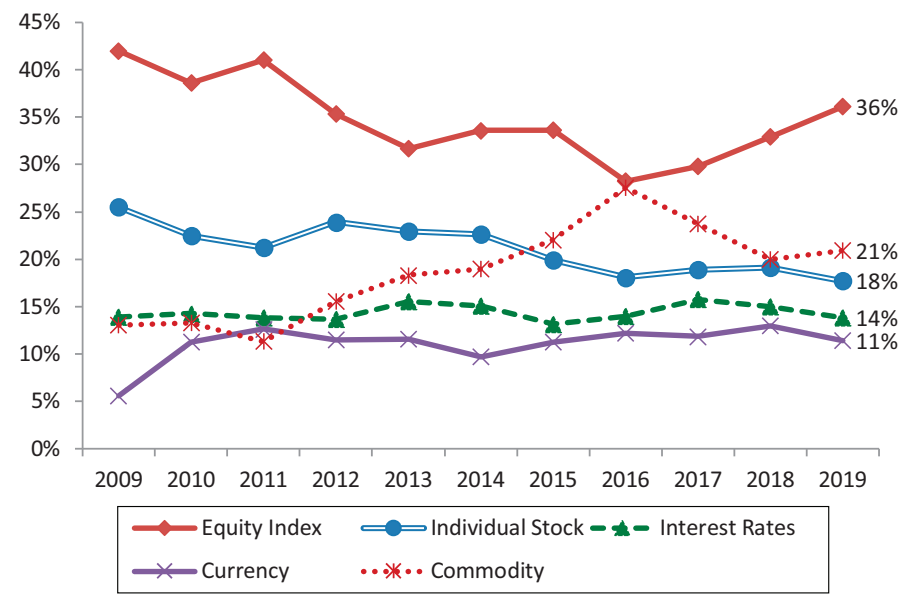

Source: FIA
Figure 4. ETD market share by underlying asset

currencies remains stable, but the market share of individual stocks and commodities has declined. It is related to the declined volatility of individual stocks and major commodity products such as crude oil and precious metals.

This paper focuses on long-term ETD [4], which have driven the growth of equity index and interest rates products. Unlike exchange-traded note (ETN), equity-linked derivatives and closed-end mutual funds, exchange traded funds (ETFs) do not have maturity and ETFs can be classified as products with very long maturities. Among the equity index products, the trading volume of ETF options has increased (Table 1). With a lot of advantages such as lower costs, instant diversification, tax efficiency and liquidity, the investment demand for ETFs has steadily increased, and the hedging and arbitrage demand for underlying ETFs also increased. It is noteworthy that long-term government bonds are more issued, and the trading volume of long-term bond futures has increased in the era of 
JDQS

28,3

152

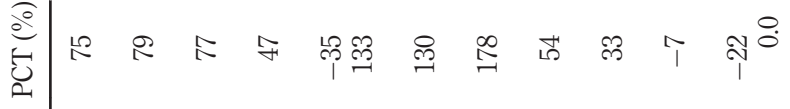

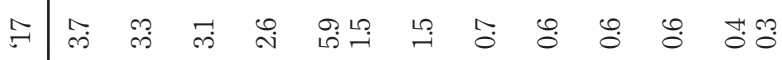

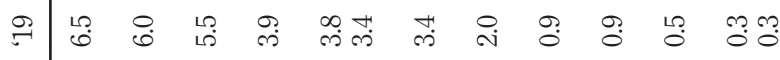

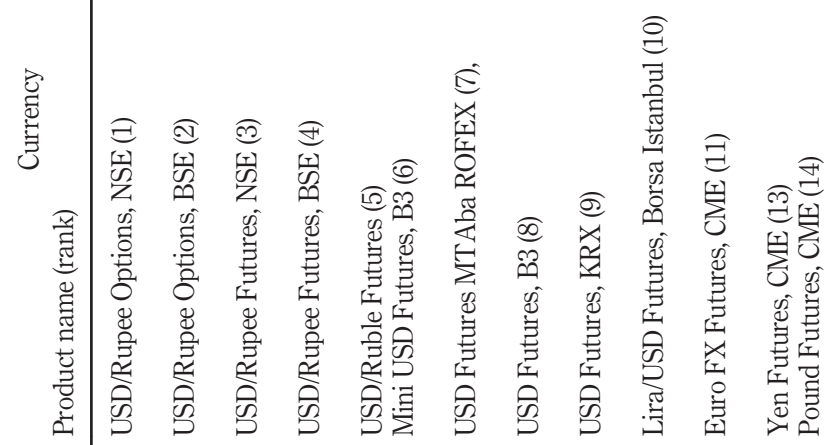

莺

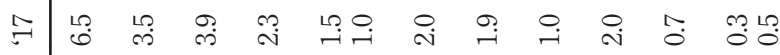

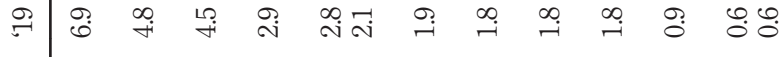

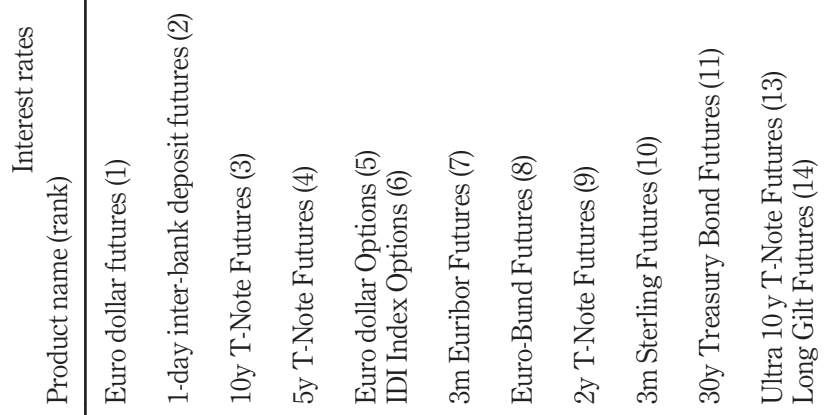

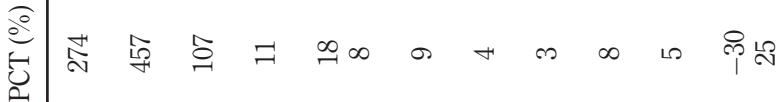

ㄱำ

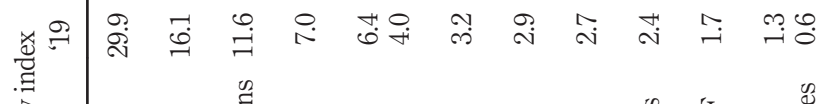

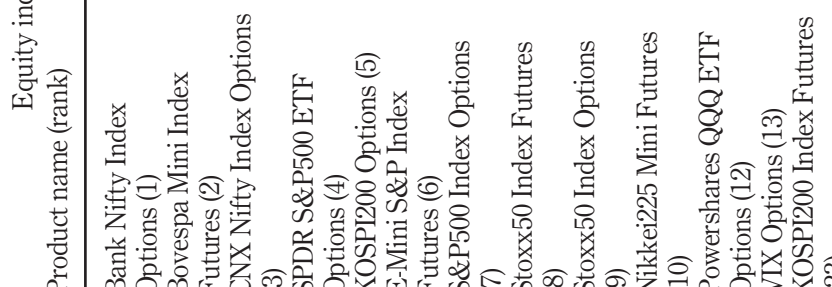

Table 1 .

Trading volume of individual ETD products 
low interest rates and aging society. Insurance companies and pension funds actively trade long-term bond futures to hedge their underlying bond portfolios with a high-duration value. As mentioned in Table 1, the trading volume of long-term bond futures such as " $30 \mathrm{y}$ Treasury Bond Futures," "Ultra 10 y T-Note Futures" and "Long Gilt Futures" increased by two digits. Lastly, VIX options can be classified as long-term ETD as VIX indexes can cover long-term implied volatility for up to one year. The Chicago Board Options Exchange (CBOE) announces the VIX3M, VIX6M and VIX1Y indexes calculated by the implied volatilities with three month, six month and one year. Owing to the VIX term structure's announcement, the VIX option with one-year expiration is listed and actively traded. Table 1 shows that the trading volume of VIX options exceeds twice the volume of Korea Composite Stock Price Index (KOSPI200) options.

Unfortunately, long-term ETD have not yet been listed on Korean derivatives market. As the low interest rates and low economic growth continues, long-term investment products such as ETF, equity-linked securities (ELS) and long-term government bonds have traded actively. Institutional investors such as Korean insurance companies, commercial banks and some pension funds have already increased their investments on ETFs and long-term government bonds. As aging accelerated, individual investors also increased to invest longterm investment products such as ETFs, ELS and long-term government bonds. Naturally, both the hedging demand and speculative demand for long-term investment products have increased. The problem is that some market inefficiencies have been observed in ETFs, ELS and long-term government bonds market. The introduction of ETD is known to reduce market inefficiencies by improving price discovery and reducing arbitrage opportunities between underlying assets and related financial products or derivatives. However, we do not have enough ETD to meet hedging demand, arbitrage-trading demand and speculativetrading demand for long-term investors. Hence, this paper aims to introduce the necessity to invigorate long-term ETD and suggests regulatory specifications for long-term ETD in Korea.

The remainder of this study is organized as follows. In Section 2, this paper points out some market inefficiencies in the Korean ETF market and introduces the necessity to activate ETF options in Korea. Section 3 includes some problems of long-term Korean bond markets and the necessity to invigorate long-term government bond futures and options. Section 4 states some side effects of retail structured products, such as ELS and derivativeslinked securities (DLS), and suggests the necessity to launch long-term Volatility Index of KOSPI (VKOSPI) futures and options. Finally in Section 5, we give a conclusion.

\section{Necessity to activate ETF options}

With the advantage of lower costs, instant diversification, trading accessibility, information transparency, tax benefits and abundant liquidity, the global ETF market has rapidly grown. The Korean ETF market is not an exception. Since Korea's first ETFs were listed on Korea Exchange (KRX) in October 2002, the Korean ETF market has grown rapidly. At the end of 2019, the total asset under management (AUM) of the Korean ETF market was KRW52tn, 22 times higher than KRW2.4tn in 2007 (Figure 5). During that period, the number of listed ETFs increased by 21 times from 21 to 450 . The growth of the Korean ETF market is remarkable, with CAGR of $29.2 \%$, compared to the public mutual funds' growth of $0.6 \%$. The Korean ETF market was the fast growing among the other developed countries' ETF market. Because of the increased participation of individual investors and foreign investors, the daily trading amount of the ETF market has also grown rapidly. The daily trading amount of the ETF market in 2019 was KRW1.34tn, accounting for 33\% of the daily 
JDQS

28,3

154

Figure 5.

The AUM of Korean

ETF market
Figure 6.

Daily trading amount of Korean ETF market

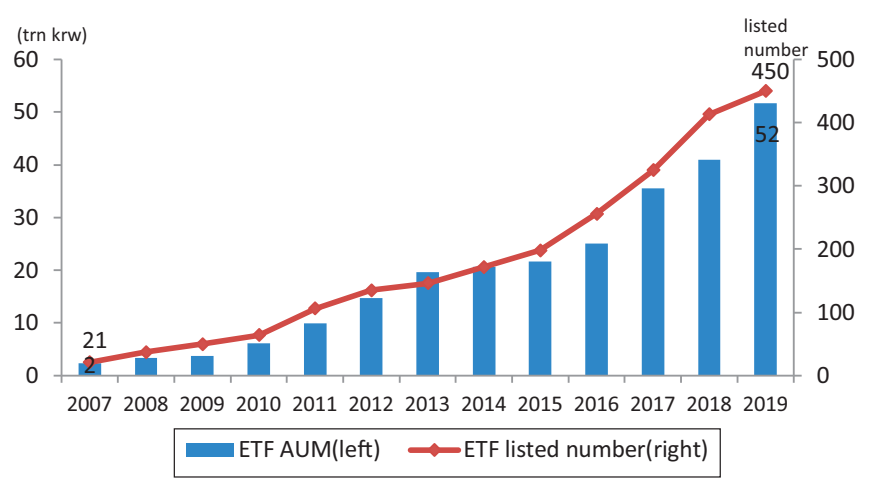

Source: KOSCOM (CHECK)

KOSPI trading volume (Figure 6). In 2007, the daily trading amount was only KRW60bn, which was less than $2 \%$ of the KOSPI trading amount at that time.

The main reason for the rapid growth of the Korean ETF market is the government's deregulation policy to invigorate the asset management industry. Like the ETF market in other countries, the Korean ETF market has prominent advantages such as tax benefits, lower costs, trading flexibility, portfolio diversification and transparency. Of these five advantages, the tax benefit is most significant in Korea. The Korean Government imposes an exemption of transaction tax $0.25 \%$ to sell ETFs. ETF liquidity providers do not have both short-selling restrictions and downtick rules. Another success factor is KRX's efforts to list various ETF products such as leveraged ETFs, inverse ETFs, synthetic ETFs and active ETFs. The participation of different types of investors also greatly contributed to the development of the Korean ETF market. In 2019, the proportion of foreign investors and institutional investors who mainly perform arbitrage and hedge trading is $30 \%$ and $29 \%$,

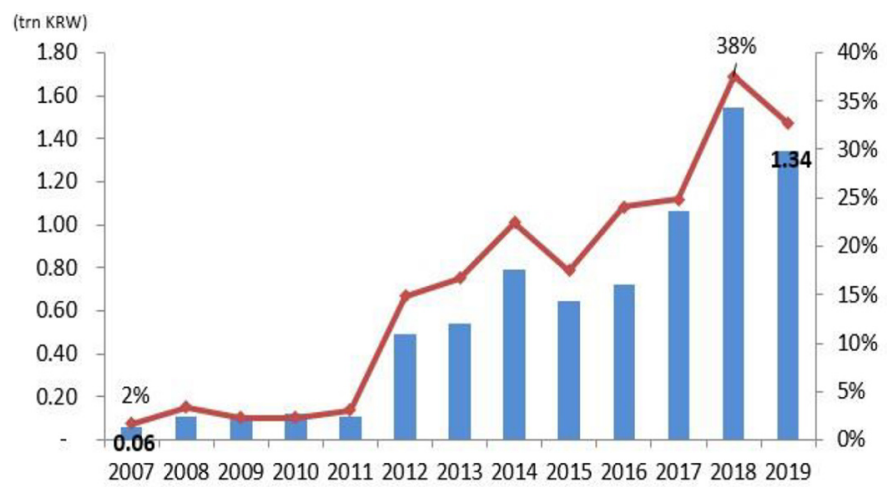

Daily Trading Amount(Left) $\longrightarrow$ Ratio of KOSPI Trading Amount(Right)

Source: $\operatorname{KOSCOM}(\mathrm{CHECK})$ 
respectively. The ratio of individual investors who trade for speculative purposes accounts for $41 \%$ of the total, the highest among three investors.

Despite the rapid growth of the Korean ETF market, there are some side effects in terms of quality. First, some derivative-based ETFs are very active, but the rest of the ETF products are not active. The daily trading amount of top seven ETFs consists of $80 \%$ of all ETF market's trading amount and the trading amount of top five derivativebased ETFs account for 65\% of all ETF market's trading amount (Table 2). Second, we have a lot of short-term speculative investors but long-term institutional investors such as National Pension Service and Retirement Pension Plans (defined benefit, defined contribution and individual retirement pension) do not actively participate in Korean ETF market. Third, some market inefficiencies are observed in Korean ETF market. For example, some ETF's discrepancy ratio, which measures the difference between the theoretical value and market value, is significantly negative. A negative discrepancy ratio of ETF means that the ETF trades more expensive than the theoretical price. The third problem can be related to both the first and the second problem, as the herding behavior of individual investors and information asymmetry between investors can cause the ETF market's inefficiencies.

Few academic studies deal with the problems of market inefficiencies about the Korean ETF market. Chung (2012) stated some market inefficiencies by showing that Korean ETFs were significantly underpriced relative to their net asset values (NAVs) and some tracking errors between ETFs' NAV and their benchmark indexes. HUR et al. (2012) also showed some significant tracking errors and discrepancies of Korean ETF market and tried to find the determinants of market inefficiencies. Kim et al. (2018a) analyzed cross-sectional ETF data and found that trading volume and institutional investors' participation ratio affected negative discrepancy of ETFs. These papers mainly focused on KOSPI200 ETFs and found that the lower the liquidity, the lower the proportion of institutional investors, and the greater the volatility, the higher the discrepancy ratio between ETFs' NAV and market value. However, the Korean ETF market has changed with the rapid growth of derivativebased ETFs. The daily trading volume of Korean ETF market has been increasing and different types of investors have participated. Despite abundant liquidity and diverse participants, it is interesting that the discrepancy ratio between ETF's NAV and market value is significant.

\begin{tabular}{|c|c|c|c|c|c|c|}
\hline Rank & ETF product name & $\begin{array}{l}\text { AUM } \\
\text { (A) }\end{array}$ & $\begin{array}{l}\text { AUM ratio [(A)/ } \\
\text { total AUM] }(\%)\end{array}$ & $\begin{array}{l}\text { Average daily } \\
\text { trading amount (B) }\end{array}$ & $\begin{array}{l}\text { Trading ratio }[(\mathrm{B}) / \\
\text { total trading }](\%)\end{array}$ & $\begin{array}{l}\text { Turn over } \\
(\mathrm{B} / \mathrm{A})(\%)\end{array}$ \\
\hline 1 & $\begin{array}{l}\text { KODEX200F } \\
\text { inverse leverage }\end{array}$ & $2,480.9$ & 5.5 & 464.7 & 20.7 & 18.7 \\
\hline 2 & KODEX Leverage & $2,476.0$ & 5.5 & 455.2 & 20.3 & 18.4 \\
\hline 3 & $\begin{array}{l}\text { KODEX } \\
\text { KOSDAQ150 } \\
\text { Leverage }\end{array}$ & 947.7 & 2.1 & 224.2 & 10.0 & 23.7 \\
\hline 4 & KODEX200 & $4,620.8$ & 10.2 & 217.9 & 9.7 & 4.7 \\
\hline 5 & $\begin{array}{l}\text { KODEX KOSDAQ } \\
\text { Inverse }\end{array}$ & 517.0 & 1.1 & 202.2 & 9.0 & 39.1 \\
\hline 6 & KODEX Inverse & $1,018.8$ & 2.2 & 133.8 & 6.0 & 13.1 \\
\hline 7 & TIGER200 & $2,550.2$ & 5.6 & 65.4 & 2.9 & 2.6 \\
\hline
\end{tabular}

Source: KOSCOM (CHECK)

Necessity to activate longterm ETD

155 
JDQS
28,3

156

This paper focuses on leverage-based ETFs and tries to analyze the degree of market inefficiency by calculating the discrepancy ratio of ETFs [5]. The discrepancy ratio of ETFs is defined as the value obtained by subtracting the ETF's NAV from the market value and dividing it by the ETF's NAV. This paper used daily based KOSPI200 ETFs, KOSPI200 leverage ETFs and KOSPI200 inverse ETFs managed by three different asset management companies from January 1, 2009 to December 31, 2019. To reflect the recent growth of derivative-based ETFs, we divided the data into two parts before and after 2016. Table 3 shows that the discrepancy ratio of leverage-based ETFs is significantly negative and is higher than that of general ETFs. Also, most derivative-based ETF's absolute value of the discrepancy ratio has increased since 2016. On the other hand, the general ETF's absolute value of discrepancy ratio has not changed significantly since 2016. We can say that the efficiency of the Korean ETF market has been getting worse and some derivative-based ETFs has had a negative impact on the market efficiency. In particular, we can guess that inverse leveraged ETFs have an even more negative effect on market efficiency. This is because that the compounding risk of inverse leveraged ETFs is three times higher than that of leveraged ETFs, and inverse leveraged ETFs have more chances of tracking errors and discrepancy ratios between NAVs and the market value.

Table 4 shows the determinants of the discrepancy ratio of ETFs based on the linear regression. For the dependent variable, we use the discrepancy ratio of ETFs. For independent variables, we use KOSPI return, return volatility, net buying pressure [6] and the previous day's discrepancy ratio of ETFs. For all ETF types, the past day's discrepancy ratio had a significant positive effect on the discrepancy ratio, and the KOSPI return and its volatility had significant effects on the discrepancy ratio of ETFs generally. The net buying pressure does not significantly affect derivative-based ETFs, unlike general ETFs. Interestingly, the KOSPI return negatively affects the discrepancy ratio of the leveraged ETFs. This implies that the leveraged ETFs are more undervalued when the KOSPI rises. The volatility of KOSPI return has a significant negative effect on the discrepancy ratio of the inverse ETFs. When the volatility increases, the inverse ETFs are likely to be undervalued. This phenomenon can be related to the contrarian trading pattern of individual investors. Individual investors tend to quickly sell the leverage ETFs when the KOSPI goes up, and they also tend to sell the inverse ETFs quickly when the volatility rises (when the KOSPI goes down).

Then how can we reduce market inefficiencies of the Korean ETF market? We have a way to induce market competition by listing ETF derivatives that play similar economic

\begin{tabular}{lcccc}
\hline Type & Company_name & All periods & Period_1 & Period_2 \\
\hline KOSPI200 & A_1 & $-0.1825 * * *(-47.2169)$ & $-0.1878 * * *(-39.2343)$ & $-0.1731 * * *(-29.8681)$ \\
ETFs & B_1 & $-0.1478 * * *(-25.5460)$ & $-0.1454 * * *(-17.6227)$ & $-0.1520 * * *(-23.1761)$ \\
& C_1 & $-0.1195 * * *(-11.9127)$ & $-0.0985 * * *(-6.4382)$ & $-0.1568 * * *(-26.8462)$ \\
KOSPI200 & A_2 & $-0.2417 * * *(-44.8222)$ & $-0.1854 * * *(-31.3008)$ & $-0.2975 * * *(-34.4769)$ \\
Leverage & B_2 & $-0.1158 * * *(-22.3955)$ & $-0.1026 * * *(-13.4261)$ & $-0.1289 * * *(-18.5326)$ \\
ETFs & C_2 & $-0.1733 * * *(-24.2386)$ & $-0.1330 * * *(-12.5308)$ & $-0.2131 * * *(-22.6204)$ \\
KOSPI200 & A_3 & $-0.2542 * * *(-55.0485)$ & $-0.1899 * * *(-36.4031)$ & $-0.3178 * * *(-45.1800)$ \\
Inverse & B_3 & $-0.0325 * * *(-8.9450)$ & $-0.0006(-0.1330)$ & $-0.0641 * * *(-11.6165)$ \\
ETFs & C_3 & $-0.0347 * * *(-9.4084)$ & $-0.0547 * * *(-12.0028)$ & $-0.0149 * * *(-2.6109)$
\end{tabular}

Table 3.

The existence test of ETF discrepancy

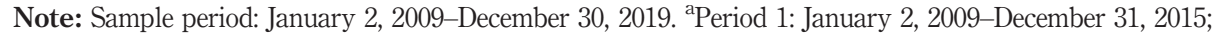
Period 2: January 2, 2016-December 30, 2019

Source: KOSCOM (CHECK) 


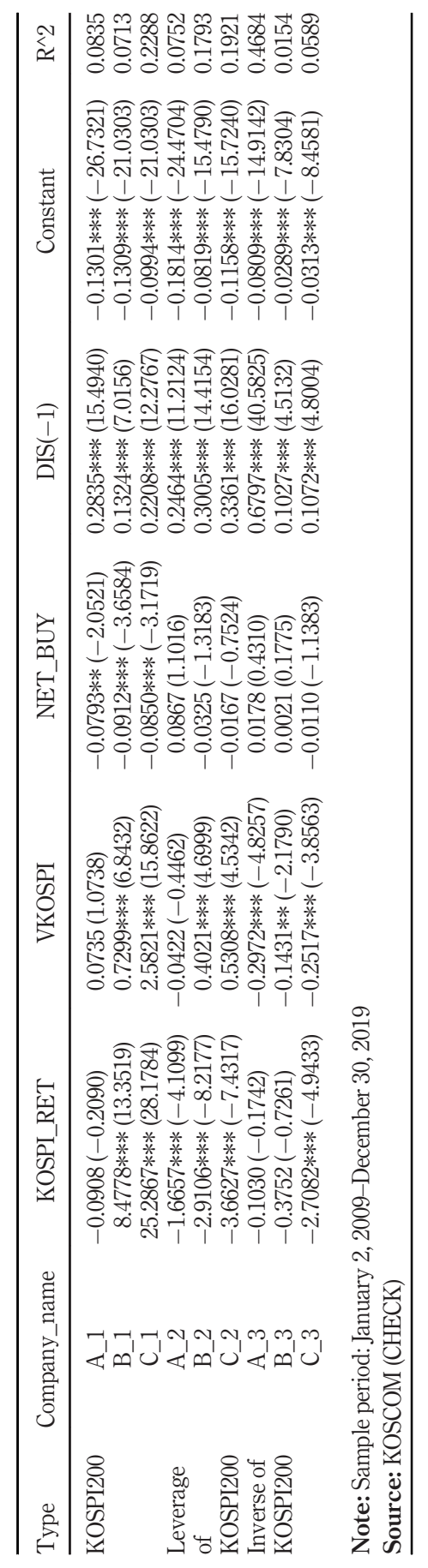


JDQS 28,3

\section{8}

roles of leverage-based ETF products. For example, both ETF futures and options can increase market efficiencies through price discovery and providing liquidity. Wang et al. (2018) showed that an efficiency measure in the Chinese ETF market has gradually improved as ETF options traded actively. Also, the investor of ETF options has the advantage of exercise any time before the final settlement day because most ETF options are American option style, unlike the general listed equity index options. As illustrated in Figure 7, the trading volume of ETF futures and options has steadily grown worldwide. Unfortunately, ETF futures and options have not yet listed on the KRX.

Specifically, it is necessary to list the American style of ETF option with underlying KOSPI200 ETFs. If we list an American ETF option with a long-term maturity of more than one year, it will not only reduce the market inefficiencies but also provide investors with the hedging vehicle of long-term risk. If both ETF call option and ETF put option trades actively, it will improve the ETF's market efficiency with the competition with leverage ETFs and inversely leverage ETFs. Besides, this paper proposes a listing of ETF options underlying the Korean Securities Dealers Automated Quotations (KOSDAQ) ETF and Sector Index ETFs. The introduction of the KOSDAQ ETF option and Sector ETF options are expected to invigorate the illiquid ETF products and increase the investment opportunity set of Korean ETF markets.

\section{Necessity to activate long-term Korea Treasury Bond (KTB) bond futures and options}

In this section, we present the necessity to activate long-term KTB bond futures and options. In Korea, foreign investors and domestic institutional investors have increased long-term government bond holdings, and the hedging demand for long-term bond portfolios has risen steadily. It is because the longer the bond's maturity, the higher the risk of interest rate fluctuations. As shown in Figure 8, The Korean Government has increased the issuance of government bonds, mainly focusing on long-term maturity bonds such as 20-year, 30-year and 50-year KTB bonds. The reason why the Korean Government increases the issuance of long-term bonds is that the demand for long-term financing is also growing to respond to aging and low economic growth. The outstanding amount of long-term KTB bond (whose maturity is over 10 year) has increased 33 times from KRW6.7tn in 2006 to KRW222.1tn in

Figure 7.

Global trading volume of ETF futures and options

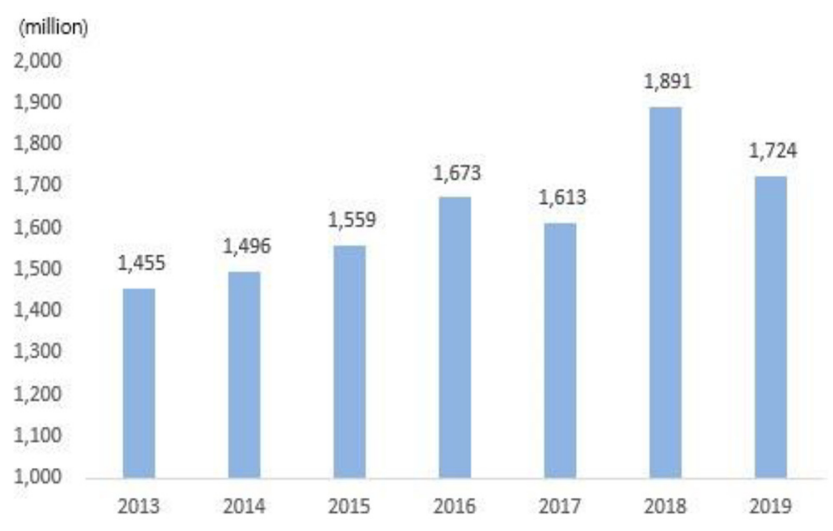

Source: World Federation of Exchanges (WFE) 


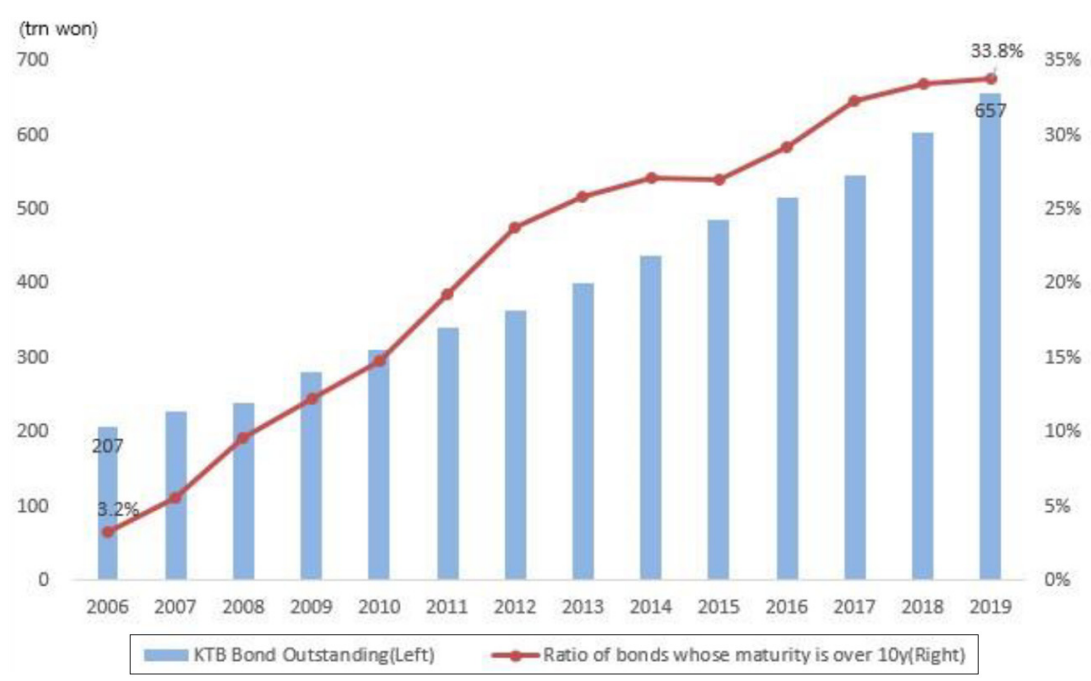

Source: KOSCOM (CHECK)
Necessity to activate longterm ETD

Figure 8.

Outstanding and long-term ratio of KTB bondsSource: $\operatorname{KOSCOM}(\mathrm{CHECK})$

2019. In 2006, the ratio of government bonds whose maturity is over 10 year was only $3.2 \%$, but in 2019, it increased to $33.8 \%$ of total government bonds.

From a demand perspective, as interest rates continue to decline and the maturity of debt increases, insurance companies and commercial banks have preferred to invest in long-term bonds. As shown in Figure 9, the duration of insurance companies' bond portfolios has more than doubled from 5.14 year in 2006 to 13.49 in 2019. The duration of other investors also

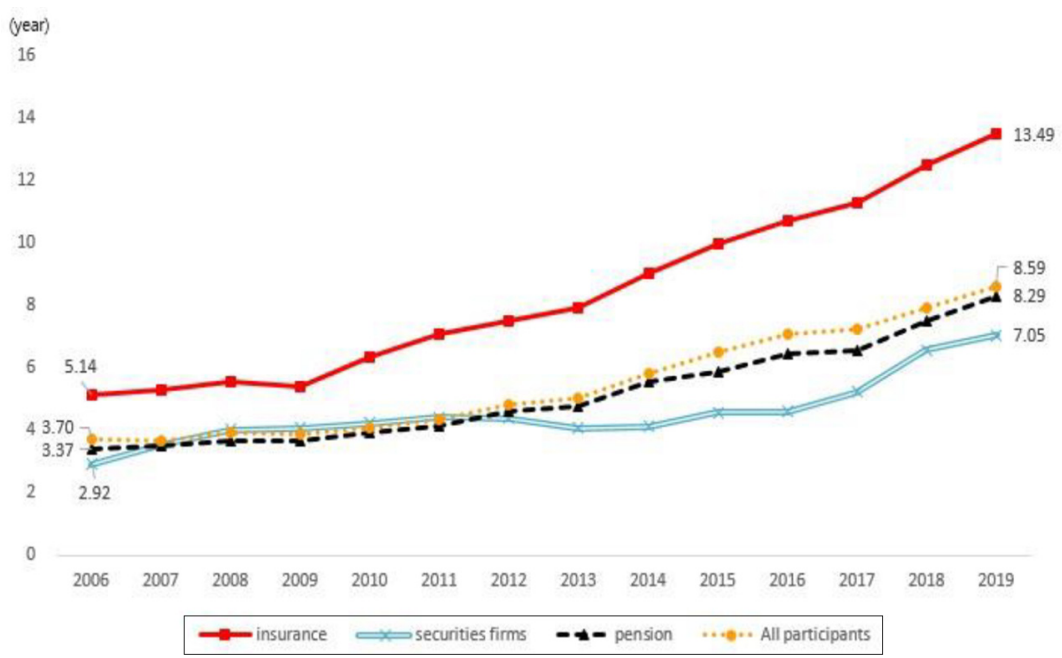

Source: KOSCOM (CHECK)

Figure 9. Duration of KTB bond by investors 
JDQS 28,3

160

increased by 2-4 times in that period. Although the duration of KTB bonds has grown rapidly, we do not have enough investment vehicles to hedge the risk of changing interest rates on long-term bonds. If the interest rate rises sharply, investors holding long-term KTB bonds can have a lot of losses. On the other hand, in the global derivatives market, long-term bond futures whose maturity is over 10 years are actively traded, as shown in Table 1.

Although the KTB bond market's trading volume has increased, we have had some market inefficiencies in the KTB bond's spot market and its derivatives market. First, the KTB bond futures price has been undervalued relative to the theoretical price of underlying KTB bond. As illustrated in Figure 10, both the theoretical basis [7] of 3-year KTB bond futures and 10-year KTB bond futures has been negative. As the futures price is undervalued relative to the spot price, investors can obtain no-arbitrage profits by buying KTB bond futures and selling the matched KTB bond portfolios. As a result of investigating the daily based theoretical basis from January 3, 2011 to December 30, 2019, the average theoretical basis of 10-year KTB bond futures was $-76.8 \mathrm{bp}$, and its absolute value was four times larger than that of the theoretical basis $(-16.8 \mathrm{bp})$ of 3-year KTB bond futures. It means that the long-term KTB bond market's efficiency is lower than that of the short-term KTB bond market. This is because the liquidity of long-term bond market is relatively low, and the number of participants in long-term bond market is less diverse than that of shortterm bond market.

Second, the volatility of the long-term KTB bond market is higher than that of the shortterm KTB bond market. In general, the longer the maturity of the bond, the higher the volatility of the bond price. This is because the risk of change in bond prices is proportional to the bond's duration. But even after controlling the duration, the volatility of long-term KTB bond is significantly higher than that of short-term KTB bond. As shown in Figure 11, the 20 -year KTB bond's annualized volatility was $19.8 \%$, which was more than twice the volatility of 10 -year KTB bond ( $8.3 \%)$. The longer the maturity of the KTB bond, the less stable the bond's price volatility. The standard deviation of the 20-year KTB bond's annualized volatility was $4.17 \%$, which was 2.7 times and 4.5 times the 10 -year and 3 -year KTB bond's annualized volatility from January 3, 2011 to December 12, 2019. The 20-year KTB bond market's high volatility may be attributed to the absence of the derivatives market for the 20-year KTB bonds. The introduction of the long-term KTB bond futures can

Figure 10 .

Basis of KTB bond futures
Basis of $3 y$ KTB bond futures

0.2

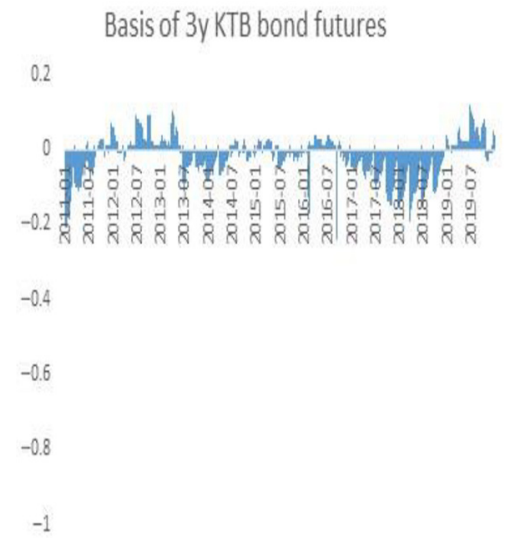

Source: KOSCOM (CHECK)

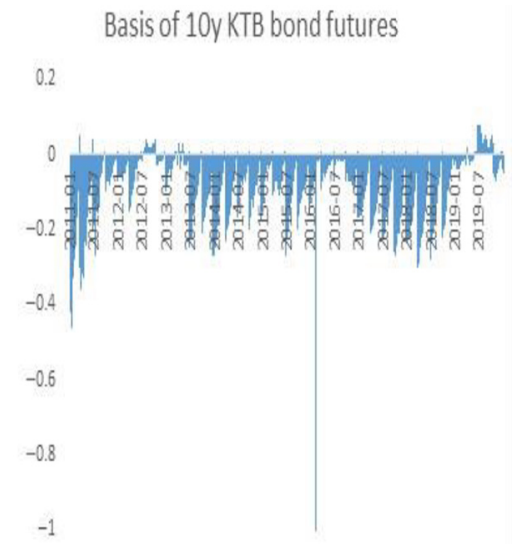

Basis of 10y KTB bond futures 


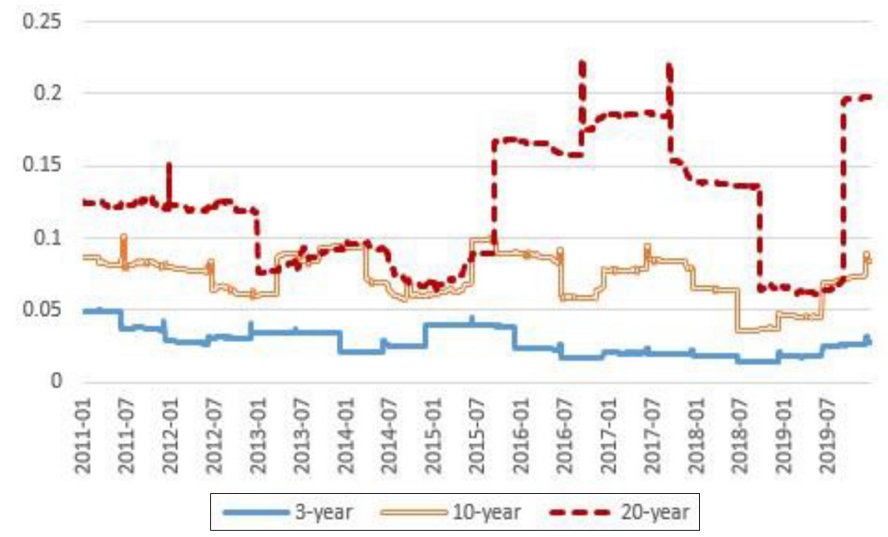

Necessity to activate longterm ETD

Source: KOSCOM (CHECK)

Figure 11.

Volatility of KTB bond market by maturity

lower the volatility of the spot long-term KTB bond market through the price discovery of long-term KTB bond futures.

Third, foreign investors have had a significant impact on the Korean bond market. Since the global financial crisis, foreigners have increased the holdings of Korean Government bonds, and they held a record high level of KTB bonds worth KRW98.5tn as of the end of December 2019. The preference for Korean Government bonds has continued as the Korean credit ratings and interest rates are at a more attractive level for overseas investors than the government bonds of other developed countries such as the USA, Germany, France and Japan. According to the announcement of the Korea Ministry of Strategy and Finance (2020), long-term foreign investors such as global asset managers, central banks and international organizations account for more than $70 \%$ of all foreign investors. Also, foreign investors have actively participated in the Korean bond futures market, such as 3-year and 10-year KTB bond futures. As shown in Figure 12, in 2019, foreigners' participation ratio in KTB bond futures was $43 \%$, the highest among major investors (domestic commercial banks, domestic securities firms, individuals, etc.). But in 2010, their participation ratio was only $5 \%$, the lowest among investors. Korea Ministry of Strategy and Finance (2020) mentioned that the KTB futures market has contributed to the development of the KTB spot market by providing information on future rates and diversifying the investor base as new investment vehicles.

Despite the increase in liquidity because of foreign participation, we have some market inefficiencies in the KTB bond market. As Park et al. (2015) stated, we can expect that when foreign investor's net buying futures increases, the interest rate implied in the KTB bond significantly declines. In this paper, we try to strictly analyze the influence of foreigners using the latest data of both 3-year and 10-year KTB bond futures. Table 5 describes the determinants of the yield change of KTB bonds based on the linear regression. For the dependent variable, we use both daily based yield change of 3-year and 10-year KTB bond. For explanatory variables, we include foreigners' net buying amount of futures (FF_NBUY) and spot bonds (FS_NBUY), the rate of the change of won-dollar exchange rate (FX_RET) and the KOSPI return (S_RET). We also try to investigate some factors that could predict the bond's price on the next trading day. As a result of the ordinary linear regression by controlling the effect of currency rate and KOSPI return, we found that market interest rates 
JDQS

28,3

162

Figure 12.

Participation ratio of KTB bond futures by investors

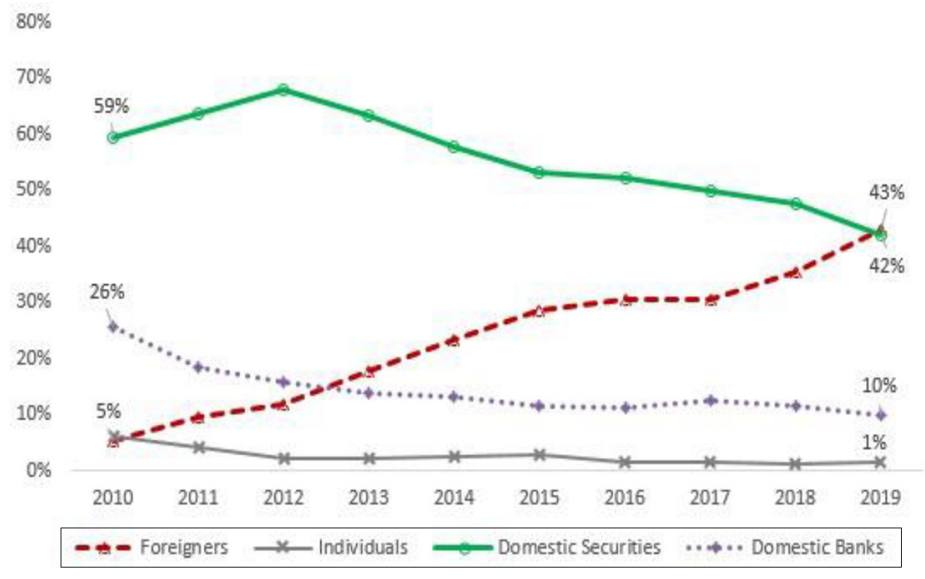

Source: KOSCOM (CHECK)

significantly decrease as foreigners purchase long position of KTB bond futures. On the other hand, the foreigner's net buying amount of spot bond market did not affect the change of market interest rates. Interestingly, the foreigner's net buying amount of 10-year KTB bond futures has more significant effect on the interest rates than that of 3-year KTB bond futures. It can be understood that the market efficiency of the 10-year KTB bond market is worse than that of the 3-year KTB bond market. To examine the impact of the recent period when foreign participation increased, we divide the sample into before and after 2016 [8]. Looking at the sensitivity on the interest rates before and after 2016, there were no significant differences.

In summary, some market inefficiencies are observed mainly in the long-term KTB bond market. To improve the long-term KTB bond's market efficiency and to provide investment vehicles for the hedging demand of long-term interest rates products, we need the policy to activate some derivatives products such as long-term bond futures and bond options. As shown in Table 1, in developed countries such as the USA and UK, ultra-long-term government bond futures and options trade actively. Many academic literatures claimed that bond derivatives play a role of increasing the bond market efficiency. Bortz (1984) stated that the introduction of bond futures helped stabilize the bond spot market. Belongia and Gregory (1984) mentioned that options on treasury bond futures traded efficiently and Cremers et al. (2020) showed that the implied volatility of treasury bond options were very informative to predict the macroeconomic variables.

We suggest listing 30-year KTB bond futures on the KRX. First of all, the 30-year KTB bond futures will provide attractive investment opportunities for domestic institutional investors and long-term foreign investors such as insurance companies, pension funds, sovereign wealth funds and national central banks. The 30-year KTB bond futures will contribute to not only the completion of the long-term yield curve but also reducing the volatility of long-term KTB bond market. This paper also suggests listing the KTB bond option with underlying KTB government bonds or KTB bond futures. As we have seen in previous studies, the introduction of KTB bond option is likely to improve the KTB bond's market efficiency and reduce the influence of foreign investors in the KTB bond market. 


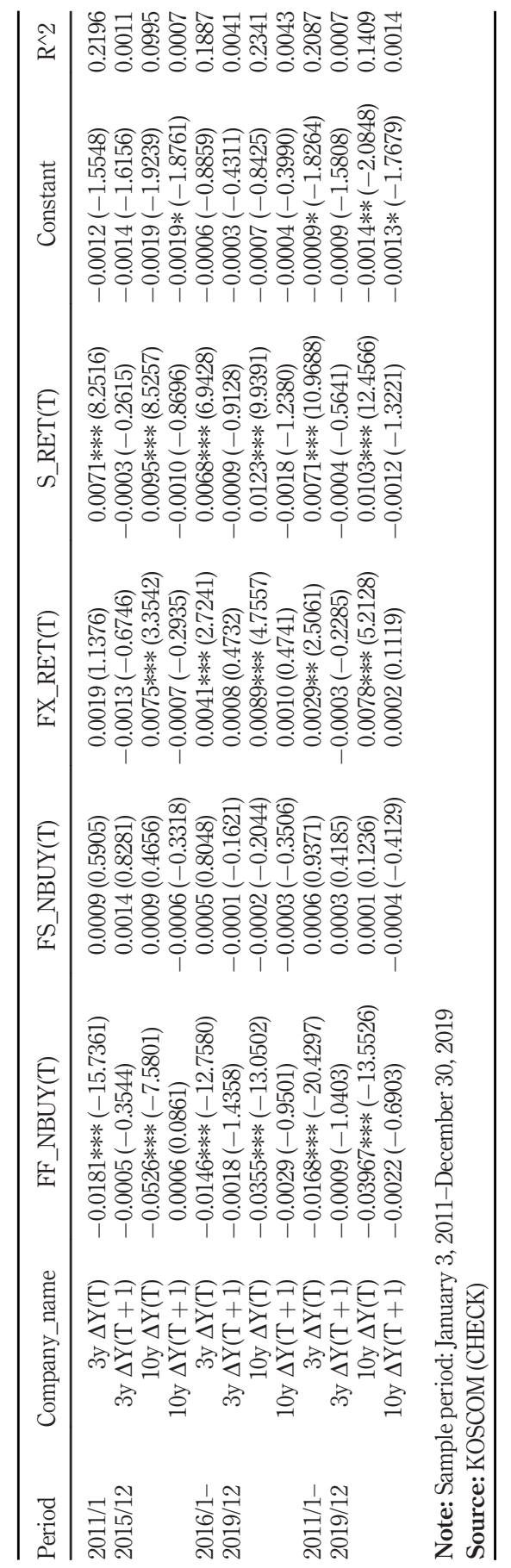


JDQS

28,3

164

\section{Necessity to activate long-term VKOSPI futures and options}

As the aging, the low interest rate and the low economic trend prolong, the demand for structured products aimed at medium risk-return profiles has steadily increased. In Korea, ELS and DLS were the fastest-growing investment products representing medium riskreturn profiles among other investment vehicles. The outstanding amount of ELS and DLS was KRW108tn, six times higher than KRW18tn in 2007 (Figure 13). In contrast, the equity mutual fund's AUM decreased by about $46 \%$ from KRW136tn to KRW74tn during the same period. The remarkable growth of ELS and DLS was backed by their higher realized returns than the return of bank deposits, shorter maturities that enable easier reinvestments and their selection of banks as the primary distribution channel to retail investors. Kang (2019) mentioned the economic benefit of long-term ELS products by showing the ELS's superior performance of the optimal portfolios for most investors.

Although the growth of ELS and DLS market is remarkable in terms of quality, some side effects in terms of quality happened to increase some risks related to the mis-selling risk and the systemic risk [9]. Regarding the mis-selling risks, the case that some major Korean banks continued the sales of derivative linked fund funds linked to the leverage of German treasury rates and skipped the procedures to explain the risks of the products was famous (Financial Supervisory Service [FSS], 2019). Concerning the systemic risk related to ELS and DLS, we had an experience that occurred in March 2020. At that time, some Korean securities firms faced margin calls form the short position of put option held for ELS hedging, when the global stock index fell sharply (Bloomberg, 2020). This paper focuses on the possibility of systemic risk during the hedging of ELS and DLS, and we examine the effect of its hedging demand on the market inefficiency. Recently Financial Services Commission (FSC) (2020) announced that it will impose tighter regulations on liquidity ratio and leverage ratio to minimize the possibility of systemic risk and reduce the increase of the ELS issuance.

First of all, the increase in ELS issuance is likely to reduce the option implied volatility of KOSPI200. To replicate the payoff structure of auto-callable ELS, securities companies should have a short position of the index put option. Since the global financial crisis, the

Figure 13.

Outstanding amount of ELS, DLS and equity fund's AUM

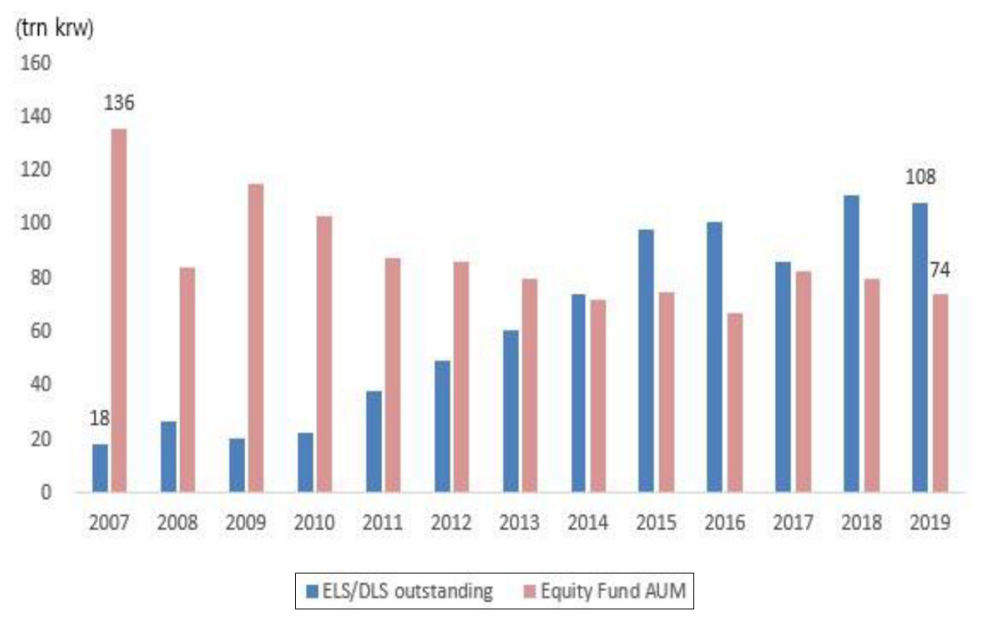

Source: KOSCOM (CHECK) 
outstanding amount of ELS has steadily increased, and the implied volatility of KOSPI200 has steadily declined. As shown in Figure 14, the VKOSPI index, which represents the level of option implied volatility of KOSPI200, fell sharply from 81.3 at the end of 2008 to 14.7 at the end of 2019. It is noteworthy that the VKOSPI index has been undervalued than the VIX index since 2011. The difference between VKOSPI and VIX was 1.54 from January 2008 to December 2010, but the difference was -0.64 from January 2011 to December 2019. It can be assumed that the reason why the recent VKOSPI index has been undervalued than the VIX index even after controlling the index return is related to the increase in ELS issuance. It is activate longterm ETD because that as the ELS issuance increases, the short position of VKOSPI also grows.

Table 6 shows the regression result about the determinant of the difference between the VKOSPI index and the VIX index. For the dependent variable, we use the monthly based difference between the VKOSPI index and the VIX index. For the independent variable, we use the difference between the KOSPI200's monthly return and the S\&P500's monthly return, the change of the VKOSPI index and the change of ELS outstanding amount. As a result of the ordinary linear regression by controlling the index return and the change of volatility index, we found that the increase in ELS outstanding amount significantly reduced the VKOSPI index relative to the VIX index, which caused the undervaluation of the Korean equity index's option market. After performing the regression analysis before and after 2011, we can guess that the influence of the ELS market on the KOSPI200 options market have increased since 2011. These results are consistent with the findings of Yoon (2014) and Ji and Rhee (2015), who find that the increase in ELS issuance reduces the implied volatility of stock index. This is because as securities firms increase the ELS issuance, the demand for selling volatility of index option (specifically underlying index's put option) increases.

Another problem is that we do not have enough investment vehicles to hedge the long-term volatility risk. As the maturity of ELS and DLS is generally three years, securities firms should hold three-year maturity options to replicate the payoff structure exactly. But securities firms are forced to trade short-term index options when the long-term options market is not active.

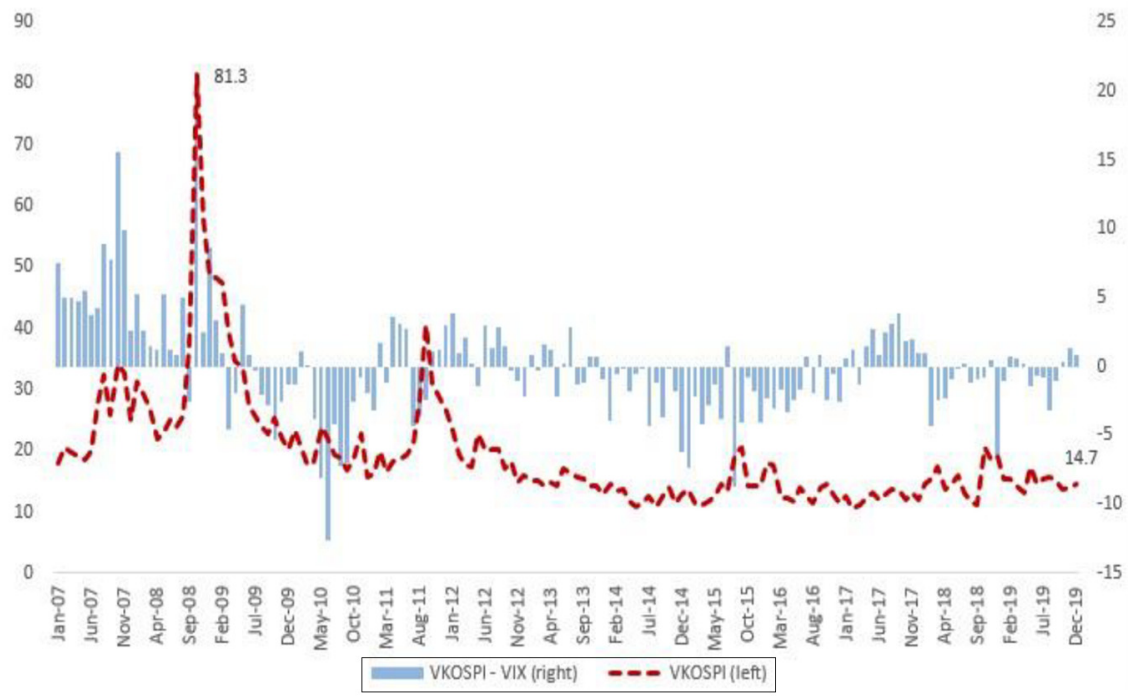

Source: KOSCOM (CHECK)

Figure 14. VKOSPI and the difference of VKOSPI and VIX 
JDQS

28,3

|

Table 6.

The determinant of difference between VKOSPI and VIX 
Actually, long-term option implied volatility does not change much. As illustrated in Figure 15, some Korean rating agencies announce the level of three-year KOSPI200 implied volatility for evaluating ELS and DLS. According to the CHECK's information, the volatility of three-year KOSPI200 implied volatility is much smaller than the volatility of one-month KOSPI200 implied volatility.

Based on the published long-term KOSPI200 implied volatility, this paper tries to find the determinants of long-term KOSPI200 implied volatility. Table 7 provides the regression result about the determinant of long-term KOSPI200 implied volatility. The attempt to explain the option implied volatility using regression analysis is based on the similar methodology of ad hoc Black and Scholes' procedures with the time to maturity suggested by Kim (2014) and Kim et al. (2018b). For the dependent variable, we use the monthly published 6-month KOSPI200 implied volatility (6-month IMVOL), 12-month KOSPI200 implied volatility (12-month IMVOL) and 36month KOSPI200 implied volatility (36-month IMVOL). For the independent variable, we use the traded one-month KOSPI200 implied volatility, the change of the VKOSPI index and the KOSPI200 return. We found that the longer the maturity of KOSPI200 implied volatility, the higher sensitivity of one-month KOSPI200 implied volatility. The longer the maturity of KOSPI200 implied volatility, the less predictive the regression model, which is consistent with Kim (2014) and Kim et al. (2018b). This means that it is difficult to accurately hedge the 3-year ELS and DLS products and securities firms can face unstable profit and loss in the hedging position of ELS and DLS products.

To effectively manage the long-term volatility risk, it is necessary to activate long-term VKOSPI futures and options. To provide the long-term volatility term structure, CBOE offers five volatility indexes - VIX9D (nine-day S\&P500 volatility index), VIX (one-month S\&P500 volatility index), VIX3M (three-month S\&P500 volatility index), VIX6M (six-month S\&P500 volatility index) and VIX1Y (one-year S\&P500 volatility index) - and their futures and options trade actively. Recently $\mathrm{CBOE}$ announced that different kinds of mini volatility index futures will be listed on August 10, 2020. Unfortunately, only the VKOSPI futures product that is based on the

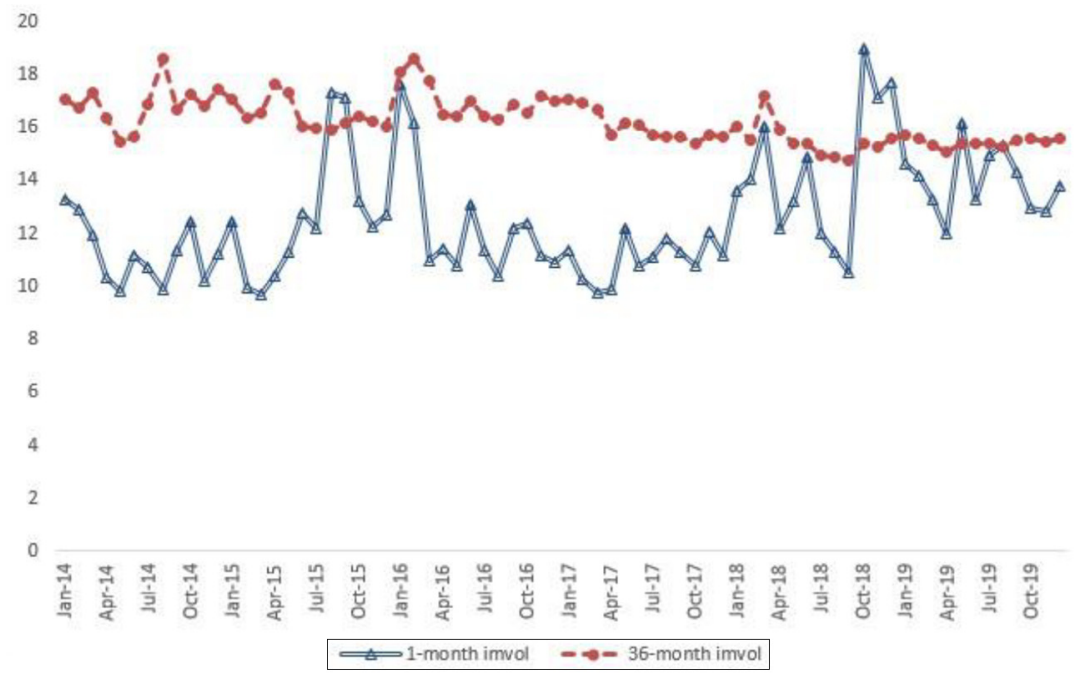

Source: KOSCOM (CHECK)

Necessity to activate longterm ETD 
JDQS

28,3

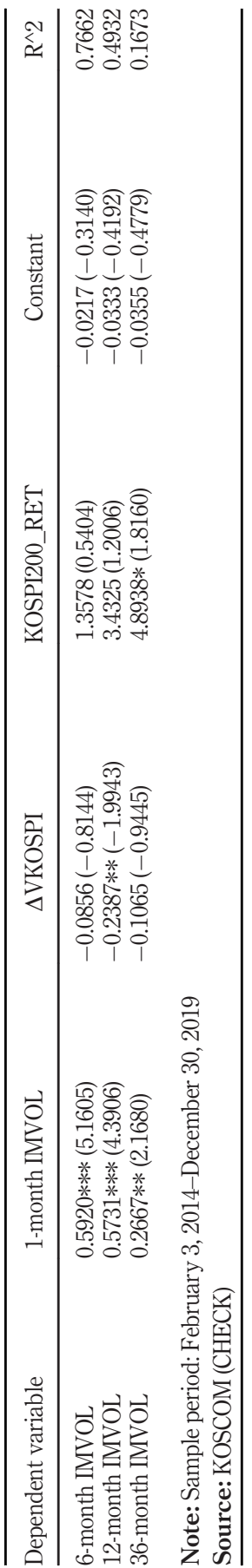

Table 7.

The determinant of long-term KOSPI200 implied volatility 
30-day future KOSPI200 volatility is listed in KRX, and the trading volume of VKOSPI futures is not active. If the long-term VKOSPI futures and some VKOSPI options are listed in KRX, Korean financial firms could not only manage long-term volatility risk, but also reduce the systemic risk.

Before listing of long-term VKOSPI derivatives, it is necessary to release an index that reflects long-term volatility of KOSPI200 market. This paper suggests a strategy that the KRX announces the three-month VKOSPI or six-month VKOSPI index by using the KOSPI200 options with a maturity less than six months. Then, it is desirable to launch the long-term VKOSPI futures and VKOSPI options based on the three-month VKOSPI or six-month VKOSPI. As the one-month VKOSPI option is not yet listed on the KRX, to improve the Korean volatility market's efficiency, the one-month VKOSPI option should be activated.

\section{Conclusion}

As the aging, the low interest rate and the low economic trend prolong, the demand for long-term financial products with longer maturity has steadily increased. To meet the hedging and speculative demand for long-term financial products such as ETFs, long-term government bonds, retail structured products and the long-term ETD have traded actively in developed markets. These long-term ETD are driving the growth of the global ETD market. Unfortunately, long-term derivatives are not listed on the KRX.

This paper aims to provide the necessity to activate long-term ETD in Korea. First, we suggest a listing of different kinds of ETF options. Unlike the ETN, retail structured products and closed-end mutual funds, ETFs have an infinite maturity and ETF options can be classified as the long-term ETD. As a result of analyzing the Korean ETF market's efficiency, we found that some derivatives ETFs are more undervalued than the theoretical NAVs. These discrepancy ratios are significantly affected by the market parameters such as KOSPI return and the VKOSPI. To reduce the market inefficiencies of the Korean ETF market, we suggest a listing of ETF options. As ETF options are generally American-style options, ETF options will contribute to providing hedging demand of long-term underlying portfolios, but will also help to reduce some market inefficiencies.

Second, we analyze the market efficiency in both the KTB bond spot market and the KTB bond futures market. Although long-term foreign investors' participation in the KTB bond market has steadily increased, we have some market inefficiencies in the KTB spot and the derivatives market. The 3-year and 10-year KTB bond futures have been undervalued relative to theoretical prices and long-term bond's volatility is higher than the short-term volatility even after controlling the bond's duration. As the foreigner's long position of futures market increases, the interest rates significantly declines. To improve the KTB bond market's efficiency and provide diverse long-term investment purposes, we suggest a listing of 30-year KTB bond futures and KTB bond options. As previous academic papers studied, the introduction of KTB bond futures and options will help stabilize the KTB bond market and improve the KTB bond market's efficiency.

Lastly, we present the necessity to activate long-term VKOSPI futures and options. As the low interest rates and the low economic growth continue, the demand for retail structured products such as ELS and DLS will increase. Unfortunately, we do not have enough hedging tools to control the long-term volatility risk that retail structured products incorporate. Hence, as the ELS issuance increases, the short-term volatility such as VKOSPI is likely to decline. This paper found that the increase in ELS outstanding significantly reduced the VKOSPI index, which caused the undervaluation of the Korean equity index's option market. To 
effectively manage the long-term volatility risk, we suggest that the KRX release an index reflecting long-term volatility risk and launch long-term VKOSPI futures and options.

\section{Notes}

1. This paper is based on the presentation in the special symposium of Asia-Pacific Association of Derivatives 2019.

2. KRX increased the multiplier for KOSPI200 options from KRW100,000 to KRW500,000 in March 2012.

3. See Sittisawad and Sukcharoensin (2018).

4. In this paper, long-term ETD mean that the maturity of the underlying asset is much longer compared to general products.

5. Generally, the market inefficiency can be measured by both tracking errors and discrepancy ratios. Derivative-based ETFs have significant tracking errors and are not stable because of the basis risk. So this paper only focuses on the discrepancy ratio of ETFs.

6. The net buying pressure is defined by the difference between the ratio of buyer-initiated trades and the ratio of seller-initiated trades in a day.

7. The theoretical basis is defined by the difference between the futures price and the future's theoretical price, which is calculated by the underlying spot bond price.

8. Period 1: January 2, 2011-December 30, 2015; period 2: January 2, 2016-December 30, 2019.

9. Please refer to Lee (2020) for the systemic risk inherent in the Korean securities industry.

\section{References}

Belongia, M.T. and Gregory, T.H. (1984), “Are options on treasury bond futures price efficiently?”, Review, Vol. 66, pp. 5-13.

Bloomberg (2020), "Market slump means Korean exotic note faces margin-call risk", Bloomberg Markets News, 2020.3.12.

Bortz, G.A. (1984), "Does the treasury bond futures market destabilize the treasury bond cash market?", Journal of Futures Markets, Vol. 4 No. 1, pp. 25-38.

Chung, J.M. (2012), "Tracking errors of ETFs that track KOSPI200”, The Korean Journal of Financial Management, Vol. 29 No. 2, pp. 91-124.

Cremers, M., Fleckenstein, M. and Gandhi, P. (2020), "Treasury yield implied volatility and real activity", Journal of Financial Economics.

Financial Services Commission (FSC) (2020), "Tightening the regulation on ELS issuance", Press Release (2020.7.30), FSC.

Financial Supervisory Service (FSS) (2019), "The progress of inspections conducted on financial firms engaged in mis-selling of DLF options", Press Release (2019.10.1), FSC.

Hur, C.S., Kang, H.C. and Eom, K.S. (2012), "Price efficiency of exchange-traded funds in Korea”, Journal of Money and Finance, Vol. 26 No. 1, pp. 39-73.

Ji, Y.G. and Rhee, J.H. (2015), “An empirical study on the hedging effects of index ELS”, Korean Journal of Futures and Options, Vol. 23 No. 3, pp. 391-420.

Kang, B.J. (2019), "Economic benefits of derivatives for long-term investments-equity linked securities", Journal of Derivatives and Quantitative Studies, Vol. 27 No. 2, pp. 211-252.

Kim, S. (2014), "Ad hoc Black and Scholes procedures with the time to maturity”, Journal of Derivatives and Quantitative Studies, Vol. 22 No. 3, pp. 465-494. 
Kim, S.W., Kim, Y.M. and Kim, G.R. (2018a), "Determinants of ETF differentials by type”, Journal of Money and Finance, Vol. 32 No. 4, pp. 151-178.

Kim, S., Byun, S.J. and Rhee, D.W. (2018b), "Ad hoc Black Scholes procedures with the time-tomaturity", Review of Pacific Basin Financial Markets and Policies, Vol. 21 No. 1, pp. 1-21.

Necessity to activate longterm ETD

Korea Ministry of Strategy and Finance (2020), "Korea treasury bonds 2019”, Korea Ministry of Strategy and Finance.

Lee, H.S. (2020), "Diagnosis and response of the systemic risk inherent in Korean securities industry", Korea Capital Market Issue Paper, 2020-13, pp. 1-21.

Park, C.Y., Mercado, R., Choi, J.H. and Lim, H.S. (2015), "Price discovery and foreign participation in the Republic Of Korea's government bond cash and futures market”, ADB Economics Working Paper Series No. 427.

Sittisawad, T. and Sukcharoensin, P. (2018), "Success factors of financial markets in Asia", Asia-Pacific Financial Markets, Vol. 25 No. 2, pp. 71-86.

Wang, J., Kang, H., Xia, F. and Li, G. (2018), "Examining the equilibrium relationship between the Shanhai 50 stock index futures and the shanghai 50 ETF options market", Emerging Markets Finance and Trade, Vol. 54 No. 11, pp. 2557-2576.

Yoon, S.J. (2014), "Structured products markets and implied volatility distortion”, Journal of Derivatives and Quantitative Studies, Vol. 22 No. 3, pp. 433-464.

\section{Corresponding author}

Hyoseob Lee can be contacted at: hslee@kcmi.re.kr

For instructions on how to order reprints of this article, please visit our website: 